\title{
EFFECTS AND AFTER EFFECTS OF INTERNMENT IN P.O.W. CAMPS
}

\author{
A presentation to a Korean ex-P.O.W. group, Camp 2, \\ on Saturday September 27, 1986.
}

By William R. Shadish *

"Gentlemen,

As you may know I was the physician for the enlisted personnel in Camp 5 on the Yalu Reservoir in early 1951 and in Death Valley before that. Because of this, many of the enlisted men and non-commissioned officers have written to me or called with health problems that had manifested themselves during our incarceration in Korean prisons. They seem to have run into a stone wall with the V.A. (Veterans Administration). They feel they are getting a deaf ear and asked for help. I want to help them and I think you all do too.

To begin, there is something you should know about the statistics of P.O.W.'s in Korea. Officially, we are told by the V.A. that there were 7140 American Prisoners of War (P.O.W.'s) taken in Korea. It is interesting to note that the missing in action figure is over 11000 . The gap of almost 4000 men is unaccounted for. You and I know there are many of the group who were prisoners but were never accounted for by the communists and who died prisoners of war. The official figure says 2701 died as P.O.W.'s. You and I know there were more than this.

If we use official figures, $38 \%$ of American P.O.W.'s in Korea died from one cause or another. This compares almost exactly to the number of American P.O.W.'s in Japan who died $(38 \%)$. The mortality for P.O.W.'s in Vietnam was $14 \%$, even though they were imprisoned a much longer period of time than we were. The death rate of American P.O.W.'s in Europe was only $2 \%$.

It is my contention that the percentage of men who died as Korean P.O.W.'s is much higher than $38 \%$. If one takes into account that there were many prisoners declared missing in action which the Chinese and Koreans have never reported as prisoners and who died as prisoners, I firmly believe that the mortality figure would be in the vicinity of 50 to $60 \%$. I know for a fact that in Death Valley alone approximately $65-75 \%$ of P.O.W.'s died in their first 3 months of captivity.

Another important factor to remember is that the Japanese and Germans had no reason to care who knew how many prisoners died in their hands. Their propaganda machine made no hay out of the fact that they took care of their prisoners, whereas you and I know that the communists in Korea tried to hide from the world how many died. Therefore the official figure of $38 \%$ death rate for Korean P.O.W.'s is in my opinion (and I believe in all truth), much too low. In addition, these deaths were not accidental but due to deliberate deprivation and dehumanization. On top of all this came severe illness.

We also know that until June of 1951 death was rampant in the prison camps. We also know that following June 1951 when the negotiations started the communists fed us better (although still poorly) and the death rate dropped to almost zero. Therefore we can say that malnutrition was the basic cause of death in the prison camps. There are many specific diseases that follow malnutrition. The worst one was pneumonia.

Pneumonia was $100 \%$ fatal at that time without antibiotics, and basically we had no antibiotics.

Dysentery and diarrhea were universal and these sapped the strength of everyone.

There were vitamin deficiencies in everyone. Psychological suppression was severe. Many other illnesses appeared including malaria, hepatitis etc. Deliberate exposure to the elements contributed to the miseries.

Because of these problems the surviving P.O.W.'s were left with a number of malfunctioning systems of the body. These have been studied a great deal in Europe particularly in Norway, France and Germany among survivors of concentration camps.

Except for a few articles there has been precious little written in the U.S. literature. I have followed every article I could locate religiously since my release and have a considerable accumulation of them. They tell of late manifestations of disease not recognised here in the U.S.. This country has never seen malnutrition such as it exists in the world. I do not care what the press talks about as starvation and hunger in the U.S.. Compared to the rest of the world all of us here know that we do not really know hunger in the U.S. at this point. Therefore the physicians, (including me at the time), had no medical school training about diseases of malnutrition, could not recognise them, and have 
few references to these. Now, however, there is literature that tells about it, even in some American journals.

Some of the problems we see now relate back to the deprivations suffered by our men in the prison camps in the 1950's. I will renumerate some of them. I think you may recognise many of them in yourselves.

1. Arthritis: European literature stresses arthritis following deprivation and malnutrition. Even in our Journal of Internal Medicine there is an excellent article that speaks of arthritis as a long range manifestation of deprivation. This is based on a number of factors:

a. A calcium deficiency in the diet (which we all experienced) that would lead to osteoporosis of the bones and disformation of the joints.

b. Repeated microtrauma of joint surfaces of a grossly malnutritioned individual with poor muscular support of bones and joints. These microtraumas and stress can later lead to arthritis. All of you have traumatic arthritis to some degree.

c. There is a disease I venture that most of your physicians don't even know about, amoebic arthritis. With amoebic dysentery there is an arthritis that occurs. It disappears with clearance of dysentery but as with any joint inflammation there may be late manifestations.

Taking into account all the above factors I will venture to say that almost universally we will all have some form of arthritis eventually.

2. Another disease we see rampant in P.O.W.'s is liver diseases. Even without hepatitis, when autopsies were performed on European concentration camp inmates every one showed fatty infiltrations of the liver, a precursor of cirrhosis, a deadly disease. All of our livers have been damaged to some extent.

3. Frostbite. Frostbite can blacken and remove toes and fingers. As in any form of disease there are subclinical forms, that is, frostbite that gives symptoms but does not destroy the digit. It may not be recognised as such but the damage has been done to the small vessels. Later in life many men write me and say that with the least bit of cold they can't use their fingers and they wonder why. That is a late result of frostbite. That disables him in the workmarket much as in my area where a lumberman is a lumberworker in cold weather.

4. Vitamin deficiencies. We have all had vitamin deficiencies across the entire range of vitamin diseases. Beriberi causes massive swollen scrotums and massively swollen legs, yet another manifestation is the beriberi heart. A full blown case would cause death from muscular collapse. In the subclinical form, the patient doesn't know he has it. However later in life as he begins to lose blood supply to the heart that has already damaged muscles he begins to show clinical manifestations of the disease. I would venture to say that every one of us has had subclinical beriberi heart disease to some extent. I have never before or since seen a group of people so severely damaged by vitamin deficiencies.

Certain deficiencies cause neuritis. You will remember the "bone aches" with pains in your legs so severe that you had to walk around in an effort to obtain relief. This is peripheral neuritis of the spinal nerves. It affects the cranial nerves also. Amongst those with us today and amongst those who have passed on, there are those whose vision left them because of the optic nerve damaged by vitamin deficiency. I for one have a hearing loss and half of you today have trouble hearing me here because of damage to the auditory nerves. This is also a vitamin deficiency residual.

5. We come now to a late problem that many of us have and none like to talk about. This involves the psychological residual that we see. Statistically about $80 \%$ of P.O.W.'s have psychological manifestations to their deprivations. How does this manifest itself? We don't go about babbling, walking on our hands or acting like a bunch of nuts. We don't like to feel that we are psychologically damaged and we suppress whatever stresses we have. However this stress syndrome shows itself in a variety of symptoms, the most common of which is anxiety, restlessness, insomnia and nightmares. My nightmares don't involve hideous beasts facing me with chainsaws. They are little stupid things like waking up in a sweat because I dreamed I went to dinner party where the "commies" came and took me back to the prison camp. That's my nightmare. I imagine each of you have had similar experiences. What it does is cut into my sleep and that is what I hate. Because of this our level of function decreases.

Many form inferiority complexes, much due to the fact that we were captured. We carry a subdued feeling of not being up to par.

There is another thing called "survivor guilt" where, simply said, we feel "why did I live and why did Joe die?". We actually feel guilty that we are here today. Such feelings can really cut into our functioning and can lead to alcoholism in many.

Particularly noted in the studies I have read is the fact that Korean ex-P.O.W.'s show considerable moodiness leading to significant difficulties in family relationships, more so than any other group of P.O.W.'s. Talk to your wives about that one. You may all think that you are functioning 
well, but there are times when our moods are up and times when they are down. This is normal in everyone but not to the degree seen in Korean ex-P.O.W.'s. This also leads, with inferiority complex, moodiness, etc, to a verified high level of unemployment in former P.O.W.'s.

There is another situation to be considered. Many ask "Why did so many of our men die and so few of the other United Nation's troops?". Remember, our men were draftees who did not want to be there in the first place and were often in a lower intelligence level with a lower ability to cope. The UN troops however were elite troops of "all volunteer units". There was the ability and esprit de corps. It is unfair to compare apples to oranges.

I want to go back one disease and that is pellagra. Pellagra is a disease of vitamin deficiency. It was universal in our prison camps. I witnessed it and will testify to that effect in any setting you wish. This disease manifests itself with three basic symptoms. That I remember from medical school and that's all I was ever taught about it. We were told to remember that with pellagra the symptoms are the "Three D's", i.e. diarrhea, dermatitis and dementia. You all remember the diarrhea. You all remember the blistering red areas on the back of your hands, your upper chest and lower neck - that's the dermatitis. However, the dementia is what I allowed to slip me by and have only recently recognised. This dementia (which in essence means feeblemindedness), occurred and one of its greatest manifestations is apathy - and you know what apathy is. During the bitter winter of 1950 and spring of 1951 when most deaths occurred, the physicians in camp coined the term "give-up-itis" or "face-the-wallsyndrome", that is, a man would be sick with diarrhea and vitamin deficiencies. At that time, as you know, that one had to have some kind of appetite to down your food. If one did not eat for several days he would die. We recognised this. When I would go on rounds amongst the enlisted men I would see a man lying in bed facing the wall. I would ask him to get up but he would not do so. I told him he was going to die and he could not care less. This is apathy. The only thing we could do since we had no medication was to harass that man so badly that he would occasionally get out of bed and say "If I get my hands on you I would kill you." I got him angry enough to get up, and so he had a chance to survive. It was a pleasure to meet some of these men later still living.

The phrase of "give-up-itis" was useful then, but I want you and the world to know that this was not really "give-up-itis", this was the dementia of pellagra - the third "D". These men died from the deliberate disease inflicted on them by the "commies" so they could begin their indoctrination program. Those who died should not be ridiculed. They are heroes who died as victims of the communist assault on them.

Age is creeping up on us and our men. Each year we are going to see more and more of the late manifestations of these diseases showing up. In 1981 the Prisoner of War Act of Congress recognised some but not all of them. For instance, it does not recognise late frostbite problems nor late beriberi problems of the heart. Nor does it recognise all the psychological residuals as it should. We must do something to help our men. If we do not help them, then who will?"

* William R. Shadish, M.D., F.A.C.S. specialises in plastic surgery in California, U.S.A. 